\title{
Stage III Distal Bile Duct Cancer AJCC v8
}

National Cancer Institute

\section{Source}

National Cancer Institute. Stage III Distal Bile Duct Cancer A/CC v8. NCI Thesaurus. Code C134817.

Stage III includes: IIIA: (T1, N2, M0); (T2, N2, M0); (T3, N2, M0); IIIB: (T4, N0, M0); (T4, N1, M0); (T4, N2, M0). T1: Tumor invading the bile duct wall with a depth less than $5 \mathrm{~mm}$. T2: Tumor invading the bile duct wall with a depth of 5-12 $\mathrm{mm}$. T3: Tumor invading the bile duct wall with a depth greater than $12 \mathrm{~mm}$. T4: Tumor involving the celiac axis, superior mesenteric artery, and/or common hepatic artery. N0: No regional lymph node metastasis. N1: Metastasis in one to three regional lymph nodes. N2: Metastasis in four or more regional lymph nodes. M0: No distant metastasis. (AJCC 8th ed.) 